\title{
WORK RELATED MUSCULOSKELETAL EFFECTS IN EMPLOYEES REPORTING TO FIELD HOSPITAL IN MONROVIA, LIBERIA, A SURVEY
}

\author{
Muhammad Usman Munir, Muhammad Tariq, Naveed Asif* \\ Pak Med IVI II, Star Base, Monrovia, Liberia, *Armed Forces Institute of Pathology/National University of Medical Sciences (NUMS) \\ Rawalpindi Pakistan
}

\begin{abstract}
Objective: To analyze work related effects on musculoskeletal system in employees reporting to Pakistan Field Hospital level II (PFH lvl II) Star Base, Monrovia, Liberia.

Study Design: Cross sectional study.

Place and Duration of Study: PFH lvl II, Star Base, Monrovia, Liberia, from Apr to Sep 2017.

Methodology: We enrolled 104 patients 30-60 years (years) consecutively, who were given a questionnaire regarding demographic and work related musculoskeletal issues. Type of work is divided into two categories as desk work/computer work and physical. Musculoskeletal issues were divided into head-ache, upper limb/ cervical issues, lower limb/nonspecific back issues and combined upper and lower limb issues. Descriptive statistics were used for variables under study. Pearson Chi square test (X2) and odd's ratios (OR) were calculated.

Results: Our study showed 48 (46\%) suffering from Musculoskeletal disorders (MSDs) as compare to 56 (54\%) who were symptom free. There were increase in percentage of MSDs with increase in age groups. Desk related issues $(58.8 \%)$ were more common in $41-50$ yrs age whereas manual work related MSDs $(72.2 \%)$ were predominant in 31-40 yrs group. Gender OR $=14.806,95 \%$ Confidence interval $(\mathrm{CI}): 3.2-68.3$ and obesity $(\mathrm{OR}=2.727$, 95\% CI: 1.0-7.1) showed strong association with work related musculoskeletal disorders (WMSDs).

Conclusion: Our study will raise awareness of work related musculoskeletal effects and measures to avoid them.

Keywords: Work related musculoskeletal disorders, Muscular pain, Physical activity.

\footnotetext{
This is an Open Access article distributed under the terms of the Creative Commons Attribution License (http://creativecommons.org/licenses/by/4.0), which permits unrestricted use, distribution, and reproduction in any medium, provided the original work is properly cited.
}

\section{INTRODUCTION}

Musculoskeletal disorders (MSDs) incorporates painful disorders of muscles, nerves and tendons. Work activities with continuous repetition, awkward posture and overuse may be cause of pain during work or rest that can develop with time. These MSDs has emerged as one of the vital causes of prolong sickness and absence from work place ${ }^{1-2}$. This adds on high cost to community in general and enterprises in particular.

Advances in current era has led to more sedentary life than ever before. Lack of physical exercise and poor postures in this sedentary life leads to increase in work related musculoskeletal disorders (WMSDs) ${ }^{3}$. Physical activity throughout the day has also an impact on the tendency of musculoskeletal disorders. Prolong sitting

Correspondence: Dr Muhammad Usman Munir, Consultant Pathologist, CMH Pano Aqil Pakistan

Received: 05 Mar 2018; revised received: 30 Aug 2019; accepted: 05 Sep 2019 position and poor knowledge of ergonomic sitting position is the prime concern. Number of hours (hrs) spent per week in front of a monitor in 1997 was 5.9 hrs which tremendously increased to $14.6 \mathrm{hrs}$ in $2003^{4}$. So, the way we spent time in different types of activities across the day has widespread effects on our health ${ }^{5}$.

There is a trend of relating cardiovascular diseases with sedentary life style and mortality leaving aside a much cornered musculoskeletal issue which has tremendous effect on quality of work and living. A part from physical factors, psychosocial effects of work related stress, depression and place of employment away from your home are also key contributors to MSDs.

Objective of this study is to highlight musculoskeletal issues of employees working in UN environment predominantly in Monrovia Liberia. So our study will facilitate health care administrators in $\mathrm{UN}$ by taking requisite measures for 
addressing this issue in broader perspective for improving general health con-ditions of UN employees across globe.

\section{METHODOLOGY}

We conducted this cross sectional study at Pakistan Field Hospital level II (PFH lvl II), Monrovia, Liberia for UN employees working in Liberia after approval of the hospital review committee. One hundred and four patients (3060 years reported to PFH lvl II for routine checkup from Apr to Sep 2017 was consecutively enrolled by non probability consecutive sampling technique. Sample size was calculated using World Health Organization Sample Size Calculator, taking confidence level of $95 \%$ and anticipated population proportion $92 \%$.

A questionnaire, comprising of demography, work related musculoskeletal disorders, risk and psychosocial factors were given to $104 \mathrm{UN}$ employees visiting PFH lvl II for checkup. Demographic data includes age in yrs, gender (male/ female) and continent of origin. Type of work was divided into three categories as desk work/ computer work, physical and weight bearing. Travel and repetitive work history was also taken. Whereas musculoskeletal issues were grouped into headache, upper limb/cervical issues, lower limb/nonspecific back issues and combined upper \& lower limb issues. Informed consent was taken from the patients. Risk factors for developing and influencing musculoskeletal issues consisted of repetitiveness, smoking, work related stress and obesity. Symptom free individuals were taken as control. Patients having musculoskeletal pain in relation to trauma, infection, malignancy or specific disease conditions were excluded.

MSDs relates with the conditions involving muscles, nerves, tendons and supporting structure of the body. According to The World Health Organization any disorder directly resulting from your working environment and performance due to certain factors has been defined as workrelated musculoskeletal disorder ${ }^{6}$. Physical activity was defined as any bodily movement pro- duced by skeletal muscles requiring energy expenditure. That could involve playing, working, active transportation, house- hold tasks and exercise training 7 .

Statistical package for social sciences version 20.0 (SPSS Inc., Chicago, IL, USA) was used for analysis of the data. Descriptive statistics were performed for demographic, risk and work related factors. Categorical variables were expressed as counts and percentages. Association between variables under study and WMSDs were shown by calculating Odd's Ratio (OR) and 95\% CI. OR $\geq 1$ was measured as contributor toward WMSDs. Pearson chi square test of independence was used to show relationship of gender, age, obesity, illness, continent and smoking with WMSDs respectively. Relationship of type of work with type of musculoskeletal issues were shown by Fisher's exact test. A $p$-value $\leq 0.05$ was considered statistically significant.

\section{RESULTS}

Our study demonstrated 48 (46\%) subjects having WMSDs whereas 56 (54\%) were symptom free. Patient characteristics of the study were shown in table-I.

Mean age was $34 \pm 5$ yrs in males and $38 \pm 7$ yrs in females. Desk related issues within middle age group (41-50 years) were predominant 10 $(58.8 \%)$ whereas in younger group (31-40 yrs) physical related MSDs 21 (72.2\%) were more seen. Combined upper \& lower limb pain was most frequent complaint 14 (29\%) followed by nonspecific lower backache 11 (23\%) (table-II).

There were $85(82 \%)$ males and $19(18 \%)$ females. Our study had alarmingly high rate 17 $(89 \%)$ of WMSDs within females (OR $=14.806)$ depicting much higher risk as compare to their male counterparts 31 (36.5\%). Combined upper and lower limb pain complaint were more in males $(31 \%)$ as compare to female who had more cases of backache $(38 \%)$.

Musculoskeletal disorders were most prevalent in Europeans (78\%) followed by Africans (62\%) and Asians (31\%). Combined upper \& 
lower limb pain was found in both Africans and Asians followed by isolated lower limb issues.

MSDs were found in 15 (65\%) obese people as compare to $35 \%$ individuals $(n=08)$ who have body mass index $<30$. So obesity and lower back pain show strong association. Fifty eight percent issues were due to physical work followed by $38 \%$ due to desk work. Combined upper \& lower limb pain was predominant in desk

\section{DISCUSSION}

Physical activity (PA) encompasses areas of occupation, leisure and sleep having varied duration and repetitiveness of muscular activity. Muscle activity is vital not only for maintaining muscle own capacity but also functioning of other organs and systems. Thirty one percent of all years lived with disability is from MSDs accounting for biggest contributor from global perspective $^{8}$. Disorders which we grouped are mostly not

Table-I: Characteristics of study population with and without work related musculoskeletal disorders.

\begin{tabular}{|c|c|c|c|c|c|c|c|}
\hline Parameter & $\begin{array}{l}\text { WMSDs } \\
(\mathrm{n}=48) \%\end{array}$ & $\begin{array}{c}\text { No WMSDs } \\
(n=56) \%\end{array}$ & $\begin{array}{c}\text { Total } \\
(n=104)\end{array}$ & $\mathrm{X} 2$ & OR & $95 \% \mathrm{CI}$ & $p$-value \\
\hline \multicolumn{8}{|l|}{ Gender } \\
\hline $\begin{array}{l}\text { Male } \\
\text { Female }\end{array}$ & $\begin{array}{l}31(36) \\
17(89)\end{array}$ & $\begin{array}{l}54(64) \\
02(11)\end{array}$ & $\begin{array}{l}85 \\
19\end{array}$ & 17.55 & 14.806 & $3.2-68.3$ & $<0.001$ \\
\hline \multicolumn{8}{|l|}{ Age (years) } \\
\hline $\begin{array}{l}31-40 \\
41-50 \\
51-60\end{array}$ & $\begin{array}{l}29(39) \\
17(65) \\
02(67)\end{array}$ & $\begin{array}{c}46(61) \\
9(35) \\
01(33)\end{array}$ & $\begin{array}{l}75 \\
26 \\
03\end{array}$ & 6.06 & - & - & 0.048 \\
\hline \multicolumn{8}{|l|}{ Continent } \\
\hline $\begin{array}{l}\text { Asia } \\
\text { Africa } \\
\text { Europe }\end{array}$ & $\begin{array}{l}18(31) \\
23(62) \\
07(78)\end{array}$ & $\begin{array}{l}40(69) \\
14(38) \\
02(22)\end{array}$ & $\begin{array}{l}58 \\
37 \\
09 \\
\end{array}$ & 12.77 & - & - & 0.002 \\
\hline \multicolumn{8}{|l|}{ Obesity } \\
\hline $\begin{array}{l}\text { No } \\
\text { Yes }\end{array}$ & $\begin{array}{l}33(41) \\
15(65) \\
\end{array}$ & $\begin{array}{l}48(59) \\
08(35) \\
\end{array}$ & $\begin{array}{l}81 \\
23 \\
\end{array}$ & 4.31 & 2.727 & $1.0-7.1$ & 0.038 \\
\hline \multicolumn{8}{|l|}{ Illness } \\
\hline $\begin{array}{l}\text { No } \\
\text { Yes } \\
\end{array}$ & $\begin{array}{l}42(45) \\
06(60)\end{array}$ & $\begin{array}{l}52(55) \\
04(40)\end{array}$ & $\begin{array}{l}94 \\
10 \\
\end{array}$ & 0.42 & 1.857 & $0.4-7.0$ & 0.514 \\
\hline \multicolumn{8}{|l|}{ Smoking } \\
\hline $\begin{array}{l}\text { No } \\
\text { Yes }\end{array}$ & $\begin{array}{l}42(46) \\
06(50)\end{array}$ & $\begin{array}{l}50(54) \\
06(50)\end{array}$ & $\begin{array}{l}92 \\
12\end{array}$ & 0.08 & 1.190 & $0.3-3.9$ & 0.777 \\
\hline \multicolumn{8}{|c|}{$\begin{array}{l}\text { WMSDs, Work related musculoskeletal disorders; X2, Pearson Chi-square test; OR, Odds ratio; CI, Confidence interval. } \\
\text { Table-II: Relationship of type of work with type of musculoskeletal issues. }\end{array}$} \\
\hline \multirow{2}{*}{\multicolumn{3}{|c|}{\begin{tabular}{l|r} 
Parameter & \\
Type of Issues & De
\end{tabular}}} & \multicolumn{2}{|c|}{ Type of Work } & & \multirow{2}{*}{$\begin{array}{l}\text { Total } \\
\text { n }(\%)\end{array}$} & \multirow{2}{*}{$p$-value } \\
\hline & & & n (\%) & Physical n (\%) & & & \\
\hline \multicolumn{2}{|c|}{ Headache } & \multicolumn{2}{|c|}{$01(2)$} & $07(15)$ & & $08(17)$ & \\
\hline Upper limb & al issues & & & $06(12)$ & & $12(25)$ & 0066 \\
\hline Lower limk & ickache & & & $11(17)$ & & $14(29)$ & 0.066 \\
\hline Combined & Lower lim & & & $06(12)$ & & $14(29)$ & \\
\hline Total & & & 38) & $30(62)$ & & 48 & \\
\hline
\end{tabular}

workers $(47 \%)$ whereas backache was more seen in physical work category (29\%) (table-II). Repetitive work was also observed as a factor in precipitating WMSDs especially in health care workers. considered as occupational except few countries where low backache and upper limb is considered as occupational ${ }^{9}$.

WMSDs encompasses multiple factors. There is a long list of inflammatory and degenerative 
disorders including inflammation of tendons, compression of nerves and myalgia affecting locomotor system in WMSDs. Functional capability decreases with age along with increase in work related musculoskeletal effects ${ }^{10}$. As is the case in our study, there was increase in percentage of MSDs with increase in age group in. Which can be emphasized by 26\% increase in MSDs in 41-50 yrs age group as compare to $31-40$ yrs. Sedentary life style is an independent risk factor effecting muscle groups directly and different body system indirectly. Repetitive work, improper position and picking heavy load are few of the commonest causes for developing of MSDs.

There is a general perception that men are more prone to WMSDs but taking working women as separate variable, they are equally or in some profession more prone to these disorders ${ }^{11}$. Women have high tendency for hip, feet and leg pain ${ }^{12}$. In our study though number of women participants are less but tendency of MSDs is found to be much more than men in their own category. Especially nonspecific low back pain is predominant complaint which is also observed among physical therapist working in kuwait ${ }^{13-15}$.

Highest prevalence of WMSDs in many studies was backache/lower limb ${ }^{16}$. Whereas in our study more cases were combination of upper and lower limb pain in an individual.

Neck pain referred to upper limb is the commonest pain described by most of office workers predominantly relating to work stress causing "Tension Neck Syndrome"17. Whereas "Repetitive strain Injuries" (RSI) is the term used for repetitive work related pain in specific muscle area in use. Repetitive work in our study are specific to desk work, health care activities involving repetitive actions, physical work on site and travelling for their particular work in field.

Working environment in UN field areas in particular and offices in general away from home, in a different country with vulnerability to any condition, may it be physical threat or fear of exposure to epidemic/health issues is one of the contributory factor in MSDs. Lack of physical activity, high demand of quality input and monotonous work adds on further ${ }^{18}$. So psychological factors and stress has much to contribute in precipitating MSDs in UN employees.

Exact cost related to MSDs are difficult to estimate due to multifactor influence. There is gross increase of $\$ 134$ billion associated with MSDs from 1986 to 2005. Absenteeism related to MSDs effects the quality of work. This cost can be decreased with addressing the issue with concern.

Our study has several strengths. It is one of its kind for UN employees working in field area. People from different continents and with different working requirements participated in our study. There are also certain limitations of our study. Target population under study was limited and results cannot be generalized to all working environment. Musculoskeletal effects exposure measurement using specific analytic techniques like electrogoniometer measurement of joint movement are not used.

\section{RECOMMENDATION}

"Intelligent Physical Exercise Training" is the concept of counterbalance and matching the deteriorating muscles due to work demand, should be incorporated in every institute.

Encouraging employees to improve muscular strength and endurance by regularly involving in sports and targeted exercises.

There is a need to develop occupational preventative programs. Targeting each body part affected by particular type of occupation in UN to improve general physical conditions and health of employees.

Moreover correct positioning of joints while sitting will improve issues relating to desk/bench workers in particular.

\section{CONCLUSION}

Work related musculoskeletal effects were a major concern especially with increase in age, obesity and poor ergonomics effecting quality of life. 


\section{CONFLICT OF INTEREST}

There is no conflict of Interest to be declared by any author.

\section{REFERENCES}

1. Bork BE, Cook TM, Rosecrance JC, Engelhardt KA. Work-related musculoskeletal disorders among physical therapists. Phys Ther 1996; 76(1): 827-35.

2. Cromie JE, Robertson VJ, Best MO. Best MO: Work-related musculoskeletal disorders in physical therapists:prevalence severity, risks and responses. Phys Ther 2000; 80(1): 336-51.

3. Chaitow L, Fritz S. Masaż leczniczy. Therapeutic massage: examination and treatment of myofascial trigger points. Elsevier Urban and Partner, Wrocław 2010. Available at: https:// medbook.com.pl/ksiazka/pokaz/id/8734/tytul/masaz-leczniczy:badanie-i-leczenie-miesniowo-powieziowych-punktowspustowych-chaitow-fritz-saulicz-elsevier-urban-\&-partner

4. Salik Y, Özcan A. Work-related musculoskeletal disorders: a survey of physical therapists in Izmir-Turkey. BMC Musculoskeletal Disor 2004; 5(1): 27-35.

5. Luttmann A, Jäger M, Griefahn B. Preventing musculoskeletal disorders in the workplace: World Health Organization; 2004.

6. Juul-Kristensen B, Søgaard K, Strøyer J, Jensen C. Computer users' risk factors for developing shoulder, elbow and back symptoms. Scand. J Work Environ. Health 2004; 30(5): 390-8.

7. Søgaard K, Sjøgaard G. Chapter 15 physiological bases of work assessment. In: Wilson JR, Sharples S, editors. Evaluation of Human Work, 4th Ed. Taylor and Francis Group; 2015.

8. Brown W, Blair SN. Good news, good news: occupational and household activities are important for energy expenditure, but sport and recreation remain the best buy for public health. Br J Sports Med 2012; 46(10): 702-3.
9. European Occupational Diseases Statistics (EODS) - Phase 1 methodology. Euro stat working papers. Population and social conditions 3/2000/E/no. 19.

10. Okunribido O, Wynn T. Ageing and work-related musculoskeletal disorders: A review of the recent literature, UK, HSE: Research Report 779, 2010.

11. Treaster DE, Burr D. Gender differences in prevalence of upper extremity musculoskeletal disorders. Ergonomics 2004; 47(5): 495-526.

12. Alrowayeh HN, Alshatti TA, Aljadi SH. Prevalence, characterristics, and impacts of work-related musculoskeletal disorders: a survey among physical therapists in the State of Kuwait. BMC Musculoskelet Disord 2010; 11: 116-22.

13. Rasmussen CD, Holtermann A, Søgaard K, Birk Jørgensen M. A multifaceted workplace intervention for low back pain in nurses' aides: a pragmatic stepped wedge cluster randomised controlled trial. Pain 2015; 156(9): 1786-94

14. Galinsky T, Waters T, Malit B: Overexertion injuries home health care workers and the need for ergonomics. Home Health Care Serv Q 2001; 20(3): 57-73.

15. Landry MD, Raman SR, Sulway C, Golightly YM, Hamdan E. Prevalence and risk factors associated with low back pain among health care providers in a Kuwait hospital. Spine 2008; 33(1): 539-45.

16. Cheney W. The lift team method for reducing back injury: a 10 hospital study. AAOHN J 1997; 45(1): 300-304.

17. Fernandes-de-Las-Penas C, Alonso-Blanco C, Cuadrado ML, Pareja JA. Trigger points in the suboccipital muscles and forward head posture in tension-type headache. Headache 2006; 43(3): 225-30.

18. Park JH, Park JH. Association among Work-Related Musculoskeletal Disorders, Job Stress, and Job Attitude of Occupational Therapists. Occup Ther Health Care 2017; 31(1): 34-43. 